Lupus Erythematosus. By E. L. DuboIs. (1966). Pp. 479, 183 figs. McGraw-Hill, New York. (£11.)

As with other inflammatory disorders of connective tissue, the image of lupus erythematosus has changed with the passage of time. Originally regarded a century ago as a chronic skin disease by Hebra and Kaposi, its visceral complications were described by Osler and the concept of a systemic disease emerged. The discovery of the L.E.-cell by Hargreaves and his colleagues heralded the present era of intensive immunological research and the disorder now lies at the very centre of the autoimmune maelstrom.

Dr. Dubois has an unsurpassed acquaintance with this disease and is the editor of a comprehensive and finely-produced book which reviews lupus erythematosus in its systemic and discoid forms. He has a distinguished team of contributors: Talbott writes on the historical background, Cruickshank on pathology, Pollak and Pirani on renal lesions, Mackay on clones, the Mieschers and Naomi Rothfield on immunology, Harvey and Shulman on false-positive tests for syphilis, and J. H. Epstein and Tuffanelli on discoid lupus.

The book is rather long for a comparatively limited subject. This is for the most part a measure of its admirable completeness-it contains nearly 1,500 references and is very well illustrated-but there is also a rather irksome tendency to repetition. Very similar accounts of experimental drug-induced lupus, quoting the same references, appear in two different places and some of the material in the chapter devoted to the L.E.-cell test is previously presented in another on immunological phenomena. These, however, are but minor editorial defects.

Dr. Dubois is certainly not content to allow others to do all the work. Over two-thirds of the book comes from his own pen, including a massive chapter of 148 pages dealing with the clinical picture of systemic lupus. Books of this sort should after all be essentially personal, with some sort of theme, rather than just a catalogue of references. Thus he tells of his experience with lupus and his ideas about its apparent increase in incidence at the Los Angeles County General Hospital since he worked there as a Fellow in Pathology assigned to haematology in 1948, the year the L.E.-cell test was described. But in the chapter on aetiology, written in conjunction with Dr. J. D. Arterberry, there is a certain lack of percipience: for example, the genetic hypothesis of Burch and Rowell is summarized without comment and we are given no help with the interpretation of this difficult work. Again, at the end of a very ful description of current (and defunct) theories of causation, the conclusion seems a little lame:

"In summary, the problem of the etiology of lupus erythematosus remains an enigma. . . . The authors believe that the two most fruitful fields for future investigation are studies seeking metabolic defects and further attempts at viral isolation. It may be that both factors play important roles in the causation of S.L.E."

But perhaps stronger views are hardly justified at present. As a review the book is completely successful, and is an essential reference work for clinician and laboratory workers who are interested in thi field.

J. T. ScotT

Arthritis and Allied Conditions. A Textbook of Rheumatology. 7th ed., 1966. Edited by JOSEPH Lee Hollander. Pp. 1355. Kimpton, London. (240s.)

The seventh edition of this well-established textbook, originally based on Comroe's Arthritis, is a slightly larger volume than previous editions. The presentation is excellent, with good type and clear diagrams and photographs. Contributors include many of the leading authorities in the sphere of rheumatic diseases in North America, and the book is packed with up-to-date expert views in this field.

There is a good chapter on the structure and function of joints, contributed by Dr. Gardner, and an up-to-date description of the newest methods of examining synovial fluid, including crystallography, by Dr. Ralph Jessar. Experimental arthritis is a topic of extreme interest at the moment, and this subject is very well dealt with by Dr. Carl Pearson.

There is a full and clearly described explanation of the various pathological aspects of rheumatoid arthritis by Dr. Leon Sokoloff.

In the large section on rheumatoid arthritis, however, because of a multiplicity of authorship, there is a rather tedious repetition of aetiological 
concepts, all the authors admitting that we have, as yet, no certain knowledge of the cause of the disease. There is also some repetition of the differential diagnosis in a number of chapters.

Dr. Morris Ziff writes authoritatively on the laboratory findings in rheumatoid arthritis, and there is an important chapter on the methods of evaluation, contributed by Dr. John Lansbury, which is of extreme relevance in view of the number of new drugs with toxic effects which are being introduced in treatment. He makes the point that, to be truly effective, a single system of evaluation should be adopted, ideally with the backing of an international body. It is satisfying to note that the methods of measurement used in the A.R.C. Gold Trial are considered to be among the best.

The subject of gold treatment is very well dealt with by Dr. Richard Freyberg, who has himself done so much work in this field.

A masterly account of systemic lupus erythematosus is contributed by Dr. Shulman, who gives a clear picture of the wide spread effects of this disease.

This reviewer criticized the previous edition because the section on osteo-arthritis was not up to the standard of the rest of the book. This has been completely rectified by the insertion of a masterly chapter on the pathology and pathogenesis of osteoarthritis by Dr. Leon Sokoloff, which makes fascinating reading. He brings forward the concept that primary changes in osteo-arthritis may well occur in the bone, rather than in cartilage. There are now methods of measuring chemical changes by new techniques, such as auto-radiography, and it is pointed out that there is, as yet, no explanation for the fact that depletion of chondroitin sulphate in osteo-arthritis cartilage does not take place to the same extent in the normal ageing process. In his concluding remarks, Dr. Sokoloff throws out the challenge that, although scientific research in osteoarthritis is as yet in an early stage, the pathological findings should not be interpreted as proof that degenerative joint disease is an inevitable concomitant of ageing.

Dr. Joe Hollander and his team of contributing editors are to be heartily congratulated on the new edition of this magnificent volume. This book can be very highly recommended to any physician or surgeon with an interest in this large group of diseases.

\title{
IV PANAMERICAN CONGRESS OF RHEUMATOLOGY
}

\author{
October 22 to 26,1967
}

The Congress will be held in Mexico City. Further information may be obtained from the General Secretary:
Dr. Gábor Kátona,

Ave Cuauhtémoc 300, Mexico, 7 D.F.

Mexico.

\section{BRAZIL}

A new Department of Rheumatology was recently opened in Rio de Janeiro by the President of the Republic. The department, under Professor J. Houli, who is also Professor of Medicine, contains a ward for 22 patients, two 2-bedded rooms, and an
Out-Patient Department, together with facilities for physiotherapy and occupational therapy. Third, fourth, and fifth-year students from the University attend for specialist teaching. 